\title{
Frequency and predictors of suboptimal glycemic control in an African diabetic population
}

\author{
Davis Kibirige' \\ George Patrick Akabwai ${ }^{2}$ \\ Leaticia Kampiire ${ }^{3}$ \\ Daniel Ssekikubo Kiggundu ${ }^{4}$ \\ William Lumu ${ }^{5}$ \\ 'Department of Medicine/Diabetic \\ and Hypertension Clinics, Our Lady \\ of Consolota Hospital, Kisubi, ${ }^{2}$ Baylor \\ College of Medicine, Children's \\ Foundation, ${ }^{3}$ Infectious Diseases \\ Research Collaboration, Kampala, \\ ${ }^{4}$ Nephrology Unit, Mulago National \\ Referral and Teaching Hospital, \\ Kampala, ${ }^{5}$ Department of Medicine \\ and Diabetes/Endocrine Unit, Mengo \\ Hospital, Mengo, Uganda
}

This article was published in the following Dove Press journal:

International Journal of General Medicine

20 February 2017

Number of times this article has been viewed

Background: Persistent suboptimal glycemic control is invariably associated with onset and progression of acute and chronic diabetic complications in diabetic patients. In Uganda, studies documenting the magnitude and predictors of suboptimal glycemic control in adult ambulatory diabetic patients are limited. This study aimed at determining the frequency and predictors of suboptimal glycemic control in adult diabetic patients attending three urban outpatient diabetic clinics in Uganda.

Methods: In this hospital-based cross-sectional study, eligible ambulatory adult diabetic patients attending outpatient diabetic clinics of three urban hospitals were consecutively enrolled over 11 months. Suboptimal glycemic control was defined as glycated hemoglobin $\left(\mathrm{HbA}_{1 \mathrm{c}}\right)$ level $\geq 7 \%$. Multivariable analysis was applied to determine the predictors.

Results: The mean age of the study participants was $52.2 \pm 14.4$ years, and the majority of them were females $(283,66.9 \%)$. The median (interquartile range) $\mathrm{HbA}_{1 \mathrm{c}}$ level was $9 \%(6.8 \%-12.4 \%)$. Suboptimal glycemic control was noted in 311 study participants, accounting for $73.52 \%$ of the participants. $\mathrm{HbA}_{1 \mathrm{c}}$ levels of $7 \%-8 \%, 8.1 \%-9.9 \%$, and $\geq 10 \%$ were noted in $56(13.24 \%)$, $76(17.97 \%)$, and $179(42.32 \%)$ study participants, respectively. The documented predictors of suboptimal glycemic control were metformin monotherapy (odds ratio: $0.36,95 \%$ confidence interval: $0.21-0.63, p<0.005$ ) and insulin therapy (odds ratio: $2.41,95 \%$ confidence interval: $1.41-4.12, p=0.001)$.

Conclusion: Suboptimal glycemic control was highly prevalent in this study population with an association to metformin monotherapy and insulin therapy. Strategies aimed at improving glycemic control in diabetes care in Uganda should be enhanced.

Keywords: suboptimal glycemic control, frequency, predictors, Africa, Uganda

\section{Introduction}

Acute diabetic complications such as diabetic ketoacidosis and chronic micro- and macrovascular diabetic complications and their associated adverse outcomes are intimately related to suboptimal glycemic control in clinical practice. Each $1 \%$ reduction in the mean glycated hemoglobin $\left(\mathrm{HbA}_{1 \mathrm{c}}\right)$ has been shown to be associated with reduction in risk of $21 \%$ for deaths related to diabetes, $14 \%$ for myocardial infarction, and $37 \%$ for microvascular complications. ${ }^{1}$ Despite this unequivocal clinical evidence that underscores the value of optimal glycemic control among diabetic patients, studies from sub-Saharan Africa and other regions of the world still document that majority of the patients in clinical care do not attain the recommended glycemic targets. ${ }^{2-4}$ This ultimately translates to increased risk of onset and progression of the fatal diabetic complications, hence increasing morbidity and mortality.

Correspondence: Davis Kibirige Department of Medicine, Uganda Martyrs Hospital Lubaga, P.O. BOX

$7 / 46$ Kampala, Uganda

Tel +256 4l 4267012

Email kibirigedavis@gmail.com 
Due to the economic growth and ensuing rapid urbanization, there is a demonstrable growing trend of diabetes mellitus (DM) and other noncommunicable diseases in Uganda. Several published community-based cross-sectional studies performed in different regions of rural and semi-urban Uganda have reported different prevalence of DM ranging from $0.4 \%$ to $9 \% .^{5-8}$ The disparity in the reported prevalence could probably be explained by the differences in the study diagnostic methods. A recently concluded representative national survey on the burden of noncommunicable diseases in Uganda using the standardized World Health Organization's stepwise approach reported a low prevalence of DM of $1.4 \%$, which is also lower than the International Diabetes Federation 2014 estimate of $4.4 \%{ }^{9,10}$

Despite this growing trend of DM in Uganda, studies assessing the levels of glycemic control and related factors among adult diabetic patients are limited. The objective of this study was to determine the frequency of suboptimal glycemic control and its related factors among adult diabetic patients attending outpatients' diabetic clinics at three urban hospitals in Kampala, the capital city of Uganda. This information obtained will be integral in influencing evidencebased policy formulation and implementation in the national and institutional diabetes management programs.

\section{Study methods}

\section{Study design, setting, and selection criteria}

This was a cross-sectional study performed between September 2014 and July 2015 in three outpatient diabetic clinics of Mulago National Referral and Teaching Hospital, a public hospital where health services are offered at no charge, and at Mengo Hospital and Our Lady of Consolata Hospital Kisubi, which are not-for-profit, faith-based hospitals where health services are offered at subsided fees. All these hospitals manage an adult diabetes clinic at least once weekly.

At each center, patients aged $\geq 18$ years with a diagnosis of diabetes confirmed by a general practitioner or physician using fasting blood glucose levels, an oral glucose tolerance test, $\mathrm{HbA}_{1 \mathrm{c}}$, or random blood sugar level in the presence of symptoms of diabetes and having been receiving care for at least a minimum of 6 months were enrolled consecutively until the desired sample size was attained. All eligible patients offered written informed consent prior to being enrolled into the study.

\section{Data collection}

Using a pretested questionnaire, information about the study participants' sociodemographic characteristics, preexisting medical conditions (coexisting hypertension and HIV), type of diabetes, age at diagnosis of DM, duration since diagnosis, and drug history were collected. All participants underwent standard anthropometric measurements to calculate the body mass index (BMI), and blood pressure (BP) was also measured. A fasting venous blood sample was obtained from each study participant after consent for determination of the $\mathrm{HbA}_{1 \mathrm{c}}$ levels and to perform a fasting lipid profile. The analysis was done at each center using a full automated COBAS ${ }^{\circledR}$ integra 400 (Roche Diagnostics GmbH, Indianapolis, IN, USA) machine.

\section{Statistical analysis}

Data were entered into Microsoft Excel database, and Stata software (College Station, TX, USA), version 12.1 was used for all statistical analysis. Patient characteristics were reported as frequency and percentage for categorical variables, mean and standard deviation for the normally distributed continuous variables, and median and interquartile range (IQR) for continuous variables that were not normally distributed.

The 2015 American Diabetes Association (ADA) guidelines of standards of care of diabetes care were used to define suboptimal glycemic control as $\mathrm{HbA}_{1 \mathrm{c}}$ levels $\geq 7 \%$. Other components of optimal diabetes care were also defined as follows: optimal BP $<140 / 90 \mathrm{mmHg}$, optimal low-density lipoprotein cholesterol $\leq 2.6 \mathrm{mmol} / \mathrm{L}$, high-density lipoprotein cholesterol $\geq 1 \mathrm{mmol} / \mathrm{L}$ for men and $\geq 1.3 \mathrm{mmol} / \mathrm{L}$ for women, triglyceride $\leq 1.7 \mathrm{mmol} / \mathrm{L}$, and total cholesterol concentrations $\leq 5 \mathrm{mmol} / \mathrm{L} .{ }^{11}$ Proportions of participants with $\mathrm{HbA}_{1 \mathrm{c}}$ levels of $<7 \%, 7 \%-8 \%$, $8.1 \%-9.9 \%$, and $\geq 10 \%$ were analyzed. In addition, we also analyzed the proportion of participants with: 1) optimal BP, glycemic, and lipid control; 2) optimal BP and glycemic control; 3) optimal BP and lipid control; and 4) optimal lipid and glycemic control.

To determine associations between the different sociodemographic, clinical, and laboratory factors and suboptimal glycemic control, bivariate analyses using $\chi^{2}$ test were performed. Multivariate analysis was then performed to identify the independent predictors. A $p$-value of $<0.05$ and confidence intervals (CIs) not including 1 were considered to be statistically significant.

\section{Ethics approval}

This study was approved by the ethics review board of Makerere University College of Health Sciences, Mengo Hospital, and Our Lady of Consolata Hospital Kisubi. 


\section{Results}

\section{Sociodemographic and clinical characteristics of the study participants}

The mean age of the study participants was $52.2 \pm 14.4$ years, with majority being females $(283,66.9 \%)$. Most of the study participants were educated to a primary or lower level of education $(165,39 \%)$ and were urban dwellers $(288,67.9 \%)$. A low prevalence of smoking $(2.35 \%)$ was reported among the study participants.

Type $2 \mathrm{DM}$ diagnosed using clinical criterion was the most common type of DM in this study population, accounting for $86.87 \%$ of the cases. Hypertension as a comorbidity and a family history of DM were also frequently seen, accounting for $68.87 \%$ and $62.26 \%$ of the participants, respectively. This study population had a relatively short duration of diabetes (median duration [IQR]: 4.5 [2-10] years) and a young age at diagnosis (median duration [IQR]: 47 [37-55] years). With regard to glycemic therapy, majority were on a combination of oral hypoglycemic therapy and conservative approach $(236,56.66 \%)$. Insulin therapy either as monotherapy or in combination with metformin was used in 188 (44.34\%) participants (Table 1).

Table I Sociodemographic, clinical, and laboratory characteristics of the study participants

\begin{tabular}{ll}
\hline Variable & $\mathbf{N}(\%)$ \\
\hline Age in years, median (IQR) & $53(43.5-62)$ \\
Gender, $\mathrm{n}(\%)$ & $140(33.02)$ \\
Male & $284(66.98)$ \\
Female & \\
Education level, $\mathrm{n}(\%)$ & $38(8.96)$ \\
$\quad$ None & $165(38.92)$ \\
Primary & $141(33.25)$ \\
Secondary & $79(18.63)$ \\
Tertiary & \\
Occupation, $\mathrm{n}(\%)$ & $212(50)$ \\
Employed & $212(50)$ \\
Unemployed & \\
Marital status, $\mathrm{n}(\%)$ & $259(61.08)$ \\
Married & $10(2.36)$ \\
Cohabiting & $47(11.08)$ \\
Single & $41(9.67)$ \\
Divorced & $67(15.80)$ \\
Widow/widowed & \\
Place of residence & $136(32.08)$ \\
Rural & $288(67.92)$ \\
Urban & $199(46.82)$ \\
Study site & $226(53.18)$ \\
Government & $10(2.35)$ \\
Private & $415(97.65)$ \\
Smoking &
\end{tabular}

(Continued)
Table I (Continued)

\begin{tabular}{|c|c|}
\hline Variable & $\mathbf{N}(\%)$ \\
\hline \multicolumn{2}{|l|}{ Known HT } \\
\hline Yes & $292(68.87)$ \\
\hline No & $132(31.13)$ \\
\hline \multicolumn{2}{|l|}{ HIV coexistent } \\
\hline Yes & $17(4.00)$ \\
\hline No & $408(96.00)$ \\
\hline \multicolumn{2}{|l|}{ FH-DM } \\
\hline Yes & $264(62.26)$ \\
\hline No & $160(37.74)$ \\
\hline \multicolumn{2}{|l|}{ Type of DM } \\
\hline Type I DM & $55(13.13)$ \\
\hline Type 2 DM & $364(86.87)$ \\
\hline \multicolumn{2}{|l|}{ Drug history } \\
\hline Diet alone & $3(0.7 \mathrm{I})$ \\
\hline Metformin alone & $79(18.59)$ \\
\hline Met + SU & I $27(29.88)$ \\
\hline Met $+S U+T Z D$ & $16(3.76)$ \\
\hline Met + Incretins & $8(1.88)$ \\
\hline Insulin alone/+Met & I $88(44.34)$ \\
\hline Statins & $89(20.94)$ \\
\hline Variable & Median (IQR), N=425 \\
\hline Age at diagnosis, years & $47(37-55)$ \\
\hline Duration with DM, years & $4.5(2-10)$ \\
\hline $\mathrm{BMI}, \mathrm{kg} / \mathrm{m}^{2}$ & $27(23-30.6)$ \\
\hline $\mathrm{HbA}_{\mathrm{Ic}}(\%)$ & $9(6.8-12.4)$ \\
\hline LDLC, $\mathrm{mmol} / \mathrm{L}$ & $2.9(2.3-3.84)$ \\
\hline HDLC, mmol/L & $1.19(0.9-1.42)$ \\
\hline $\mathrm{TC}, \mathrm{mmol} / \mathrm{L}$ & $4.82(4 . \mid-5.7 I)$ \\
\hline $\mathrm{TGL}, \mathrm{mmol} / \mathrm{L}$ & $1.6(1.23-2.2)$ \\
\hline $\mathrm{SBP}, \mathrm{mmHg}$ & $139(124-155)$ \\
\hline $\mathrm{DBP}, \mathrm{mmHg}$ & $80(73-91)$ \\
\hline
\end{tabular}

Note: Copyright $\odot 20$ 17. Dove Medical Press. Reproduced from Lumu W, Kampiire L, Akabwai GP, Kiggundu DS, Kibirige D. Statin therapy reduces the likelihood of suboptimal blood pressure control among Ugandan adult diabetic patients. Ther Clin Risk Manag. In press 2017.19

Abbreviations: IQR, interquartile range; DM, diabetes mellitus; $\mathrm{HT}$, hypertension; FH, family history; SU, sulfonylureas; Met, metformin; Pio, pioglitazone; BMI, body mass index; $\mathrm{HbA}_{1 \mathrm{c}}$, glycated hemoglobin; LDLC, low-density lipoprotein cholesterol; HDLC, high-density lipoprotein cholesterol; TC, total cholesterol; TGL, triglycerides: SBP, systolic blood pressure; DBP, diastolic blood pressure; TZD, thiazolidinediones.

\section{Glycemic, BP, and lipid control among the study participants}

Of the study participants enrolled, results of 423 participants were complete, and so these were used to analyze the extent of glycemic, BP, and lipid control. The median $\mathrm{HbA}_{1 \mathrm{c}}$ was 9 (6.8-12.4) \%. Only 112 (26.48\%) of the study participants had optimal glycemic control as defined by the 2015 ADA guidelines of diabetes management (ie, $<7 \%$ ). Majority of the participants had suboptimal glycemic control, defined as $\mathrm{HbA}_{\mathrm{lc}} \geq 7 \%(311,73.52 \%)$.

Considering other components of diabetes care, a very small proportion of the study participants had optimal glycemic, lipid, and BP control collectively $(9,2.1 \%)$. Optimal glycemic and BP control, glycemic and lipid control, and lipid 
Table 2 Extent of glycemic, BP, and lipid control among the study participants $(n=423)$

\begin{tabular}{|c|c|}
\hline $\mathrm{HbA}_{\mathrm{Ic}}(\%)$ & $\mathbf{N}(\%)$ \\
\hline$<7$ & I I 2 (26.48) \\
\hline 7-8 & $56(13.24)$ \\
\hline $8.1-9.9$ & $76(17.97)$ \\
\hline$\geq 10$ & $179(42.32)$ \\
\hline $\begin{array}{l}\text { All L (LDLC, HDLC, TC, TGL collectively), BP, } \mathrm{HbA}_{\mathrm{lc}} \\
\text { normal }\end{array}$ & $9(2.1)$ \\
\hline $\mathrm{HbA}_{\mathrm{Ic}}-\mathrm{BP}$ normal & 59 (I3.9) \\
\hline $\mathrm{HbA}_{\mathrm{Ic}}-\mathrm{L}$ normal & $15(3.6)$ \\
\hline L-BP normal & $27(6.4)$ \\
\hline
\end{tabular}

Abbreviations: L, lipid profile; $\mathrm{HbA}_{\mathrm{lc}}$, glycated hemoglobin; $\mathrm{BP}$, blood pressure; LDLC, low-density lipoprotein cholesterol; HDLC, high-density lipoprotein cholesterol; TC, total cholesterol; TGL, triglycerides.

plus BP control were documented in only $13.9 \%, 3.6 \%$, and $6.4 \%$ of the participants, respectively (Table 2 ).

\section{Sociodemographic, clinical, and laboratory characteristics of the study participants at bivariate analysis}

At bivariate analysis, metformin monotherapy $(p<0.005)$, use of insulin therapy either as monotherapy or in combination with metformin $(p<0.005)$, and systolic BP $(p=0.01)$ were statistically significant. There was a trend toward significance for age of the study participants $(p=0.052)$. Table 3

Table 3 Bivariate analysis of sociodemographic and clinical characteristics associated with suboptimal glycemic control

\begin{tabular}{|c|c|c|c|c|}
\hline \multirow[t]{2}{*}{ Characteristic } & \multicolumn{3}{|c|}{$\mathrm{HbA}_{\mathrm{lc}} \geq 7 \%, \mathrm{HbA}_{\mathrm{lc}}<7 \%$, OR $(95 \% \mathrm{Cl})$} & \multirow[t]{2}{*}{$p$-value } \\
\hline & n (\%) & $n(\%)$ & & \\
\hline \multicolumn{5}{|l|}{ Age, years } \\
\hline$\leq 40$ & $30(20.69)$ & $82(29.50)$ & $0.62(0.39-1.01)$ & 0.052 \\
\hline$>40$ & $115(79.31)$ & $196(73.52)$ & & \\
\hline \multicolumn{5}{|l|}{ Gender } \\
\hline Male & $4 \mathrm{I}(29.50)$ & $98(0.50)$ & $0.79(0.5 \mathrm{I}-\mathrm{I} .25)$ & 0.325 \\
\hline Female & $71(25.00)$ & $213(75.00)$ & & \\
\hline \multicolumn{5}{|l|}{ Type of hospital } \\
\hline Government & $56(28.14)$ & I43 (7I.86) & $0.85(0.55-1.3 \mathrm{I})$ & 0.466 \\
\hline Private & $56(25)$ & $168(75)$ & & \\
\hline \multicolumn{5}{|c|}{ Place of residence } \\
\hline Rural & $28(20.74)$ & $107(79.26)$ & $1.57(0.96-2.57)$ & 0.067 \\
\hline Urban & $84(29.17)$ & $204(70.83)$ & & \\
\hline \multicolumn{5}{|l|}{ Smoking } \\
\hline Smoker & $3(30.00)$ & $7(73.00)$ & $0.84(0.21-3.30)$ & 0.799 \\
\hline Nonsmoker & $109(26.39)$ & $304(73.61)$ & & \\
\hline \multicolumn{5}{|l|}{ Coexisting HT } \\
\hline Yes & $78(26.7 \mathrm{I})$ & $214(73.29)$ & $0.96(0.60-1.54)$ & 0.870 \\
\hline No & $34(25.95)$ & $97(74.05)$ & & \\
\hline \multicolumn{5}{|l|}{ DM type } \\
\hline Type I DM & $13(23.64)$ & $42(76.36)$ & $1.21(0.62-2.35)$ & $0.57 \mid$ \\
\hline Type 2 DM & 99 (27.27) & $264(72.73)$ & & \\
\hline \multicolumn{5}{|c|}{ Family history of DM } \\
\hline Yes & $70(26.52)$ & $194(73.48)$ & $0.99(0.64-1.55)$ & 0.982 \\
\hline
\end{tabular}

(Continued)
Table 3 (Continued)

\begin{tabular}{|c|c|c|c|c|}
\hline \multirow[t]{2}{*}{ Characteristic } & \multicolumn{3}{|c|}{$\mathrm{HbA}_{\mathrm{Ic}} \geq 7 \%, \mathrm{HbA}_{\mathrm{Ic}}<7 \%$, OR $(95 \% \mathrm{Cl})$} & \multirow[t]{2}{*}{$p$-value } \\
\hline & n (\%) & n (\%) & & \\
\hline No & $42(26.42)$ & $117(73.58)$ & & \\
\hline \multicolumn{5}{|l|}{ HIV comorbidity } \\
\hline Yes & $5(29.4 I)$ & 12 (70.59) & $0.86(0.30-2.50)$ & 0.780 \\
\hline No & $107(26.35)$ & $299(73.65)$ & & \\
\hline \multicolumn{5}{|c|}{ Median years with DM } \\
\hline$\leq 10$ & $89(27.55)$ & $234(72.45)$ & $1.27(0.75-2.16)$ & 0.368 \\
\hline$>10$ & $23(23.00)$ & $77(77.00)$ & & \\
\hline \multicolumn{5}{|l|}{$\mathrm{BP}, \mathrm{mmHg}$} \\
\hline$\leq 140 / 90$ & $55(23.8 I)$ & $176(76.19)$ & $0.74(0.48-1.14)$ & 0.173 \\
\hline$>140 / 90$ & $57(29.69)$ & $135(70.31)$ & & \\
\hline \multicolumn{5}{|l|}{$\mathrm{BMI}, \mathrm{kg} / \mathrm{m}^{2}$} \\
\hline$\leq 25$ & $44(26.83)$ & $120(73.17)$ & 1 & 1 \\
\hline $25.1-29$ & $23(21.90)$ & $82(78.10)$ & $1.31(0.73-2.33)$ & 0.363 \\
\hline$\geq 30$ & $42(30.43)$ & $96(69.57)$ & $0.84(0.51-1.38)$ & 0.489 \\
\hline \multicolumn{5}{|c|}{ Glucose-lowering therapy, n (\%) } \\
\hline $\begin{array}{l}\text { Metformin } \\
\text { alone }\end{array}$ & $4 \mathrm{I}(52.56)$ & $37(47.44)$ & $0.23(0.14-0.40)$ & $<0.005$ \\
\hline Met + SU & $34(26.77)$ & $93(73.23)$ & $0.98(0.6 I-1.57)$ & 0.929 \\
\hline Incretins + Met & $\mathrm{I}(12.50)$ & $7(87.50)$ & $2.56(0.3 I-2 I .10)$ & 0.366 \\
\hline $\begin{array}{l}\text { Met + SU + } \\
\text { TZD }\end{array}$ & $6(37.50)$ & $10(62.50)$ & $0.59(0.21-1.66)$ & 1.309 \\
\hline $\begin{array}{l}\text { Insulin alone/+ } \\
\text { Met }\end{array}$ & $27(\mid 4.36)$ & I6I (85.64) & $3.38(2.04-5.59)$ & $<0.005$ \\
\hline $\begin{array}{l}\text { On statin therapy, } \\
n(\%)\end{array}$ & $26(29.2 I)$ & $63(70.79)$ & $0.84(0.500-I .4 I)$ & 0.511 \\
\hline \multicolumn{5}{|l|}{ LDLC, mmol/L } \\
\hline$\leq 2.6$ & $45(29.22)$ & $109(70.78)$ & $1.26(0.80-1.97)$ & 0.32 \\
\hline$>2.6$ & $64(24.7 I)$ & 195 (75.29) & & \\
\hline \multicolumn{5}{|l|}{ HDLC, mmol/L } \\
\hline$<1$ & $33(26.61)$ & $76(26.39)$ & $1.01(0.62-1.63)$ & 0.962 \\
\hline$\geq 1$ & $76(26.39)$ & $212(73.61)$ & & \\
\hline \multicolumn{5}{|l|}{$\mathrm{TC}, \mathrm{mmol} / \mathrm{L}$} \\
\hline$\leq 5$ & $64(27.95)$ & $165(72.05)$ & $1.19(0.76-1.85)$ & 0.443 \\
\hline$>5$ & 45 (24.59) & $138(75.41)$ & & \\
\hline \multicolumn{5}{|l|}{$\mathrm{TGL}, \mathrm{mmol} / \mathrm{L}$} \\
\hline$\leq 1.7$ & $65(27.78)$ & $169(72.22)$ & $1.18(0.76-1.84)$ & 0.466 \\
\hline$>1.7$ & $44(24.58)$ & 135 (75.42) & & \\
\hline \multicolumn{5}{|c|}{ Non-HDLC, mmol/L } \\
\hline$<3.4$ & $49(29.52)$ & I I 7 (70.48) & $1.29(0.83-2.02)$ & 0.248 \\
\hline$\geq 3.4$ & $60(24.39)$ & $186(75.61)$ & & \\
\hline \multicolumn{5}{|l|}{ TC/HDLC ratio } \\
\hline$<4.5$ & 68 (29.06) & $166(70.94)$ & $1.37(0.87-2.15)$ & 0.170 \\
\hline$\geq 4.5$ & $41(23.03)$ & I 37 (76.97) & & \\
\hline \multicolumn{5}{|l|}{$\mathrm{SBP}, \mathrm{mmHg}$} \\
\hline$<140$ & $45(21.03)$ & 169 (78.97) & $0.56(0.36-0.88)$ & 0.01 \\
\hline$\geq 140$ & 67 (32.06) & $142(67.94)$ & & \\
\hline \multicolumn{5}{|l|}{$\mathrm{DBP}, \mathrm{mmHg}$} \\
\hline$<90$ & $72(26.37)$ & 201 (73.63) & $0.99(0.63-1.55)$ & 0.948 \\
\hline$\geq 90$ & $40(26.67)$ & $110(73.33)$ & & \\
\hline
\end{tabular}

Abbreviations: OR, odds ratio; $\mathrm{Cl}$, confidence interval; DM, diabetes mellitus; BP, blood pressure; HT, hypertension; FH, family history; SU, sulfonylureas; Met, metformin; $\mathrm{BMI}$, body mass index; $\mathrm{HbA}_{\mathrm{Ic}}$, glycated hemoglobin; LDLC, low-density lipoprotein cholesterol; HDLC, high-density lipoprotein cholesterol; TC, total cholesterol; TGL, triglycerides; SBP, systolic blood pressure; DBP, diastolic blood pressure; TZD, thiazolidinediones. 
Table 4 Independent predictors of suboptimal glycemic control on multivariable analysis

\begin{tabular}{|c|c|c|c|c|}
\hline \multirow[t]{2}{*}{ Variable } & \multicolumn{2}{|l|}{ Unadjusted } & \multicolumn{2}{|c|}{ Adjusted analysis } \\
\hline & OR (95\% Cl) & $p$-Value & OR (95\% CI) & p-Value \\
\hline $\begin{array}{l}\text { Place of } \\
\text { residence }\end{array}$ & $1.57(0.96-2.57)$ & 0.067 & $0.64(0.38-1.07)$ & 0.089 \\
\hline $\begin{array}{l}\text { Metformin } \\
\text { monotherapy }\end{array}$ & $0.23(0.14-0.40)$ & 0.000 & $0.36(0.2 I-0.63)$ & $<0.005$ \\
\hline Insulin therapy ${ }^{a}$ & $3.38(2.04-5.59)$ & 0.000 & $2.4 \mathrm{I}(\mathrm{I} .4 \mathrm{I}-4.12)$ & 0.001 \\
\hline
\end{tabular}

Note: aEither in monotherapy or in combination with metformin.

Abbreviations: $\mathrm{OR}$, odds ratio; $\mathrm{Cl}$, confidence interval.

summarizes the sociodemographic, clinical, and laboratory characteristics of the study participants in association with suboptimal glycemic control at bivariable analysis.

\section{Independent predictors of suboptimal glycemic control at multivariate analysis}

The documented predictors of suboptimal glycemic control were only glucose-lowering therapies, ie, metformin monotherapy (odds ratio [OR]: $0.36,95 \% \mathrm{CI}: 0.21-0.63$, $p<0.005$ ) and insulin therapy (OR: $2.41,95 \%$ CI: $1.41-4.12$, $p=0.001)$. Place of residence of the study participants was not statistically significant after multivariate analysis (OR: 0.64, 95\% CI: $0.38-1.07, p=0.089$ ) (Table 4).

\section{Discussion}

This study documents a high prevalence of suboptimal glycemic control among this ambulatory Ugandan adult diabetic population. The identified independent predictors of suboptimal glycemic control were only glucose-lowering therapies, ie, metformin monotherapy and insulin therapy.

Comparable high frequencies of suboptimal glycemic control have been reported in several studies performed in Africa and other developing countries. In the largest sub-Saharan African study assessing the quality of diabetes care in 2,352 type $2 \mathrm{DM}$ patients, the mean $\mathrm{HbA}_{1 \mathrm{c}}$ was $8.2 \% \pm 2.4 \%$, with $71 \%$ of the patients having suboptimal $\mathrm{HbA}_{1 \mathrm{c}}$, defined as levels $>6.5 \%{ }^{2}$ Other similar studies in Ethiopia, South Africa, and Uganda have documented frequencies of suboptimal glycemic control to be between $64.7 \%$ and $79.2 \% .{ }^{12-15}$ In another large study of 1,179 diabetic patients from Eastern Europe, Asia, Latin America, and Africa called the International Diabetes Mellitus Practice Study (IDMPS), suboptimal glycemic control defined as $\mathrm{HbA}_{1 \mathrm{c}}$ greater than $7 \%$ was noted in $75 \%$ of the patients. ${ }^{16}$

The probable reasons to explain these high proportions of patients with suboptimal glycemic control in our developing countries, as demonstrated in some of the studies, include lack of access to $\mathrm{HbA}_{1 \mathrm{c}}$ monitoring, inequitable access to diabetes medication, delay, and fear to initiate and optimize insulin therapy among health care workers, low levels of patient education, and, generally, knowledge gaps in diabetes management among the health care workers. ${ }^{2,14-16}$

\section{Independent predictors of suboptimal glycemic control}

The two identified independent predictors were metformin monotherapy and insulin therapy. Metformin monotherapy was noted to have a protective effect against suboptimal glycemic control in our study. Similarly in the IDMPS, among patients on oral glucose-lowering therapy, the use of fewer oral therapies was associated with attainment of optimal glycemic goals in all the regions studied. ${ }^{16}$ Fewer medications in clinical practice generally tend to improve patient drug adherence and compliance, hence resulting in better treatment outcomes. Metformin monotherapy in clinical practice might reflect mild severity or early disease with easy attainment of glycemic goals.

Insulin therapy was noted to increase the odds of suboptimal glycemic control. This has also been reported in similar studies from Ethiopia and Brazil. ${ }^{12,17}$ However, poor glycemic control cannot be directly attributed to insulin therapy per se. In diabetes care, there is an observed clinical inertia, which can be defined as the failure to initiate, establish appropriate targets, and optimize treatment so as to achieve treatment goals with regard to insulin therapy. ${ }^{18}$ This could be due to the physician's lack of knowledge and experience with insulin use and the patient's fear of insulin-induced hypoglycemia and weight gain. There is also hesitancy among patients to accept insulin treatment due to fear of pain of injections, cost, hypoglycemia, and weight gain. Insulin use is, thus, reserved for only patients with severe disease or for patients later in the disease course and for those that have failed to reach glycemic goals despite very high doses of oral glucose-lowering drugs.

\section{Study limitations}

Due to the small sample size and cross-sectional nature of the study as well as its performance in an urban hospital setting, we cannot establish temporal relationships and also generalize to the entire adult diabetic population seeking care in Uganda.

\section{Conclusion and recommendations}

Suboptimal glycemic control is a highly prevalent finding among adult diabetic patients affecting about seven in ten patients. Metformin monotherapy and insulin therapy either in monotherapy or in combination with metformin were observed to be independent predictors of suboptimal glycemic control. There is an imperative need to improve optimal glycemic management in adult diabetic patients. 


\section{Acknowledgment}

The authors would like to recognize and thank all the study participants who participated in this study and the entire research team, especially the nursing staff, at the respective study sites who assisted in patient identification and enrollment.

\section{Disclosure}

DK works in the medical unit of GlaxoSmithKline, Uganda. None of the described work was funded by GSK, and the views expressed here are solely the author's. The authors report no other conflicts of interest in this work.

\section{References}

1. Stratton M, Adler A, Neil H, et al. Association of glycaemia with macrovascular and microvascular complications of type 2 diabetes (UKPDS 35): prospective observational study. BMJ. 2000;321(7258): 405-412.

2. Sobngwi E, Ndour-Mbaye M, Boateng K, et al. Type 2 diabetes control and complications in specialised diabetes care centres of six sub-Saharan African countries: the Diabcare Africa study. Diabetes Res Clin Pract. 2012; 95:30-36.

3. Pablos-Velasco P, Parhofer K, Bradley C, et al. Current level of glycaemic control and its associated factors in patients with type 2 diabetes across Europe: data from the PANORAMA study. Clin Endocrinol (Oxf). 2014;80:47-56.

4. Pinchevsky Y, Butkow N, Chirwa T, Raal F. Glycaemic, blood pressure and cholesterol control in 25629 diabetics. Cardiovasc J Afr. 2015; 26:188-192.

5. Mayega R, Guwatudde D, Makumbi F, et al. Diabetes and pre-diabetes among persons aged 35 to 60 years in eastern Uganda: prevalence and associated factors. PLoS One. 2013;8(8):e72554.

6. Maher D, Wasswa L, Baisley K, Karabarinde A, Unwin N, Grosskurth H. Distribution of hyperglycaemia and related cardiovascular disease risk factors in low-income countries: a cross-sectional population-based survey in rural Uganda. Int J Epidemiol. 2011;40:160-171.
7. Mondo C, Otim M, Akol G, Musoke R, Orem J. The prevalence and distribution of non-communicable diseases and their risk factors in Kasese district, Uganda. Cardiovasc J Afr. 2013;24:52-57.

8. Lasky D, Becerra E, Boto W, Otim M, Ntambi J. Obesity and gender differences in the risk of type 2 diabetes mellitus in Uganda. Nutrition. 2002;18(5):417-421.

9. Bahendeka S, Wesonga R, Mutungi G, Muwonge J, Neema S, Guwatudde D. Prevalence and correlates of diabetes mellitus in Uganda: a populationbased national survey. Trop Med Int Health. 2016;21(3):405-416.

10. International Diabetes Federation. IDF Diabetes Atlas. 6th ed: 2014 update. Available from: http://www.idf.org/diabetesatlas/. Accessed January 29, 2015.

11. Standards of Medical Care in Diabetes 2015: summary of revisions. Diabetes Care. 2015;38(1):S4.

12. Abebe S, Berhane Y, Worku A, Alemu S, Mesfin N. Level of sustained glycemic control and associated factors among patients with diabetes mellitus in Ethiopia: a hospital-based cross-sectional study. Diabetes Metab Syndr Obes. 2015;8:65-71.

13. Amod A, Riback W, Schoeman H. Diabetes guidelines and clinical practice: is there a gap? The South African cohort of the International Diabetes Management Practices Study. JEMDSA. 2012;17(2):85-90.

14. Webb E, Rheeder P, VanZyl D. Diabetes care and complications in primary care in the Tshwane district of South Africa. Prim Care Diabetes. 2015;9:147-154.

15. Kibirige D, Atuhe D, Sebunya R, Mwebaze R. Suboptimal glycaemic and blood pressure control and screening for diabetic complications in adult ambulatory diabetic patients in Uganda: a retrospective study from a developing country. J Diabetes Metab Disord. 2014;13:40.

16. Chan J, Gagliardino J, Baik S, et al. Multifaceted determinants for achieving glycemic control: the international diabetes management practice study (IDMPS). Diabetes Care. 2009;32:227-233.

17. Viana L, Leitão C, Kramer C, et al. Poor glycaemic control in Brazilian patients with type 2 diabetes attending the public healthcare system: a cross-sectional study. BMJ Open. 2013;3:e003336.

18. Strain W, Bluher M, Paldanius P. Clinical inertia in individualising care for diabetes: is there time to do more in type 2 diabetes? Diabetes Ther. 2014; 5:347-354.

19. Lumu W, Kampiire L, Akabwai GP, Kiggundu DS, Kibirige D. Statin therapy reduces the likelihood of suboptimal blood pressure control among Ugandan adult diabetic patients. Ther Clin Risk Manag. In press 2017.
International Journal of General Medicine

\section{Publish your work in this journal}

The International Journal of General Medicine is an international, peer-reviewed open-access journal that focuses on general and internal medicine, pathogenesis, epidemiology, diagnosis, monitoring and treatment protocols. The journal is characterized by the rapid reporting of reviews, original research and clinical studies across all disease areas.

\section{Dovepress}

The manuscript management system is completely online and includes a very quick and fair peer-review system, which is all easy to use. Visit http://www.dovepress.com/testimonials.php to read real quotes from published authors. 